\title{
Teaching Contemporary and the Role of the Teacher in the Classroom with the Student Centered
}

\author{
Dr. Prof. Ass. Fatmir Vadahi \\ University of Shkodra "Luigi Gurakuqi" Albania, \\ Faculty of Education, \\ fatmirvadahi@gmail.com
}

Mr. sc. Dritan Ceka

University of Shkodra "Luigi Gurakuqi" Albania,

Faculty of Education dritanceka@hotmail.com

Mr. sc. Anila Jaku

University of Shkodra "Luigi Gurakuqi" Albania, anila2010@hotmail. co. uk

\begin{abstract}
Major changes occurring in the last session in the field of technical and technological tools and recent International Development in the field of education have made a fundamental change in contemporary teaching. Traditionally in Albania education is conducted in the traditional manner teacher was the one who had the main burden while the students were told otherwise spectator or regular headphones. Various changes and reforms in the education field has necessitated changing the way of teaching and have made changes. Today education conditions have changed and taking into account the various investment funds, whether from government or various international organizations have made the traditional method has been implemented to date in Albania be replaced with modern teaching method or the method with different spoken teacher in class with the student center. Today modern teaching techniques have made teaching more attractive for students but also for teachers. Work instructional techniques develop students' creativity, freedom in expression, convenience class. Also classroom setting has a special significance, because it helps to escort students among themselves and work in groups through modern techniques and learning is more productive for students. Modern techniques are very important factor in the work of teachers today they assist their learning except that they also help influence the creativity of the students in the classroom, or otherwise the students to feel the comfort of the people in the class.
\end{abstract}

Keywords: Teaching, modern techniques, teachers, students

\section{Introduction}

Given that we live in a time that is rich in information and resources to acquire knowledge, it is important to develop skills for knowledge acquisition faster and better. Teaching is a complex relationship between teachers and students, among students themselves, among them students, between students and school administration. Teaching requires a complex skills and attitudes of teachers. Some claim that teaching is based on the knowledge of teachers to plan and develop learning, knowledge about the content to be taught to students. Teaching traditional school far more care about the learning content than the student who learns that content. Furthermore learning process based on verbal learning without being associated with environ- in which the students live and work. Teaching is not just an intellectual and practical activity, but also moral. Effective teaching is a result of positive emotions. A good teacher tries to understand the feelings, desires, inner thoughts pupils, discusses advises and guides. The role of teachers in the classroom with the student center is to facilitate 
the learning of children based on their needs and interests. In student-centered classroom students get the content, gain skills and develop as individuals and to the whole class is determined by knowing the interests and needs of students in the classroom. Teaching is a form of emotional labor or otherwise can say is emotional practice which involves emotional understanding and is an inseparable part of the work of the pupils in the classroom. From the perspective of working with the students at the center and work based on competences, it is important to motivate students learning resources and stimulate their progress. While textbooks are valuable sources of learning, student's access information learned not only in textbooks. Access and use of a broad spectrum of learning resources, to plan and to realize the learning process in the classroom will avoid learning the routine and provide learning opportunities for learning. Teachers use instructional resource centers to enrich their materials and methods teachers use learning resources that encourage and promote the acquisition of relevant knowledge, developing skills, values and attitudes that lead to the gradual mastery of key competencies. Teaching traditional school far more care about the learning content in school than pupils who learns that content. Furthermore learning process based on verbal learning without being associated with the environment in which the student lives and works. Teaching is associated learning is an activity where the teacher interacts with one or more students.

\section{The purpose of the research and study objectives}

The purpose and objectives of this research is to investigate whether teachers work more modern teaching techniques that NIAC student centered classroom, a teacher knowledge NIAC modern teaching techniques, he use it in everyday work with students etc.

\section{Research question, hypothesis and methodology of the paper}

This goal is a description of the current situation in Shkodra schools and Ulcinj. The survey was conducted from grade 1 to 9 in elementary schools. Development has been directly questions the teacher responses were received from teachers who are in the process of working with the students.

The hypothesis of the current teachers or have knowledge of modern teaching techniques that aim NIAC learner-centered?

4. The importance of research initiated by the fact that the training of students or teacher training absent additional funding is not made any teaching training who are in the work that a long time and still today use or words work traditional teaching methods.

\section{Topics of this research are:}

To distinguish the activities of the students in the classroom.

To distinguish methods for the assessment of knowledge of students by teachers.

To distinguish between the methods that teacher uses during the lesson.

To assess the need for change in teaching and learning, taking into consideration the student needs.

\section{Contemporary Teaching}

Teaching upgrade the modern based on the knowledge, skills and values that offers an experience that bring students from certain areas they come from. The teacher is the one who should recognize at the same time create a range of teaching strategies to respond to the needs, interests, motivations, attitudes, experiences and requirements of students in the classroom. In the process of teaching is important that the teacher is confident in the abilities and potential students. Students learn easier and better when they are encouraged, when they assessed the level of proficiency of their learning. In this way students will be more motivated to create standard, take responsibility for the manner, style and their 
opportunities for learning. It is very important that teaching be based on the principle of linking the work of the school with everyday life. This means to put the students in a real life context, where his knowledge will find fulfillment in real life situations and problematic. Learning should be seen as something that belongs directly to them, as something that belongs to them to build and enrich it. Every modern society is interested to form responsible citizens, capable citizens who will lead the national processes and human values in global society. This will not be achieved without recognition of respect for human rights and freedoms in general, and without recognition and realization of children's rights in particular.

Modern teaching among others encourage and enables the student to be active in the learning process, pays attention to the needs, interests of students, develop initiative and independence for students to learn, develop students' responsibility for achievements to highlight the needs, interests different talents and learning, inclusion of students actively etc. Teaching contemporary inter alia requires the active inclusion of students, individual and group skills, develops skills mutual learning, develops organizational skills and work such as the division of responsibilities, finding the right information, educational placement, teacher interaction students etc. Based on contemporary teaching strategies concluded that essential feature of the success of student learning is precisely the "partnership between teachers and pupils who finds himself realized numerous methods and interactive techniques that constitute its content" where one program that promotes interaction is Developing Critical Thinking Reading and Writing.

\section{Planning and organization of learning}

Planning and organization of learning requires more than traditional planning of teaching hours, always based on the achievement of learning outcomes to key competencies, according to the potential and interests that students encounter, then individual differences of the different styles of learning communication and their reports in class, active participation of students in the implementation of new learning new situation, engage students in active mode. It is clear that we cannot talk about perfect mastery of teaching, but based on the content of the work of teachers, in our experience and in the European advanced beyond; a good lesson must necessarily contain some main elements:

To be completely clear objectives are feasible.

Students are given the opportunity to organize their work.

Lessons are to gain students' interest.

Language students be rich and developed etc.

Planning and organization of learning is fundamental to teaching masters involved in the practical work of teachers in the classroom and they are: planning and preparation, development of the teaching, learning management, classroom climate, assessment of student progress, reflection on teaching and appraisal etc. these are some of the basic skills of teaching with student centered. Without learning planning is one of the distinguishing features of teacher mastery as it relates to the daily operation of teachers in the classroom. It's more important to focus on knowledge of the subject teachers and students in early learning, presentation, continue learning, reinforcement learning outcome in classroom management, student motivation, communication with students in their assessment and teaching. There are many opinions today to assess the mastery of teachers. Although there are many opinions and different, they have the following common side. When the teacher teaching methods selected based on previous knowledge and abilities of students. Strategies that he selects students should bring success. This does not mean that we should hesitate to use new methods and techniques. Although personal preferences affect the methodological choices, the teacher continually seeks opportunities to further develop teaching skills.

\section{Teaching and assessment process}

Changes in society make the teachers to cope with new tasks in their classes. They face different ways of teaching and other tasks that must be tailored to the students and how they learn, although they are not sure what other changes await in the future. In recent decades, political, social, economic and environmental, as well as the development of science and technology have made every aspect related to school to be reviewed and revised, including the assessment of students. Until recently, the assessment in the classroom is considered as a mechanism for providing a learning index, which has 
taken into account a predicted pattern: teachers teach, test the knowledge of students, see their achievements based on those and more then that. Schools in the 21st Century represent the idea of individualized approach which respects the abilities and efforts of each child to create his own way of learning. Teachers who represent this opinion are directed towards the child that is in center the learning process, while the teacher only creates the environment which reflects this perspective. Assessment as an integral part of teaching and learning should serve to prepare the students for the skills needed to achieve the 21 st century differs from traditional assessment or words contemporary 21 st century.

\begin{tabular}{|c|c|}
\hline Traditional assesment & Contemporary assesment \\
\hline $\begin{array}{l}\text { In traditional evaluation is often provided in writing with } \\
\text { alternative response assessment means open to } \\
\text { evaluation forms }\end{array}$ & Assesment consists of open ways to teach \\
\hline Time for assesment & $\begin{array}{l}\text { Timing of assessment Assessment is continuous } \\
\text { throughout the entire school year }\end{array}$ \\
\hline $\begin{array}{l}\text { The grade depends only on the basis of a knowledge } \\
\text { control rating depends on many things }\end{array}$ & Asssesment depeds of many things \\
\hline Assesment depends on grades & Rating marked with grade rating is oriented progress \\
\hline $\begin{array}{l}\text { Assessment instruments are subject to change norms for } \\
\text { assessment instruments subject to different criteria }\end{array}$ & $\begin{array}{l}\text { Assessment instruments are subject to change norms for } \\
\text { assessment instruments subject to different criteria }\end{array}$ \\
\hline $\begin{array}{l}\text { The evaluation process is separate from the teaching } \\
\text { evaluation process related to the learning process }\end{array}$ & Assesment is related bu learning proccess \\
\hline $\begin{array}{l}\text { Success depends on the memorization of information } \\
\text { presented in the certain }\end{array}$ & $\begin{array}{l}\text { Success depends on the memorization of information } \\
\text { presented in the certain moments of success is } \\
\text { determined through cooperation and negotiation over a } \\
\text { longer period }\end{array}$ \\
\hline Knowledge depends on linguistic skills & $\begin{array}{l}\text { Understanding measured by linguistic ability (language) } \\
\text { and logical / mathematical understanding is measured in } \\
\text { the choice of real-life problems }\end{array}$ \\
\hline $\begin{array}{l}\text { The correct answer is testimony to the efforts and learning } \\
\text { of students' views of students used to understand their } \\
\text { perception and that those views are included in the next } \\
\text { content resides teaching }\end{array}$ & $\begin{array}{l}\text { The views of students used to understand their perception } \\
\text { and that those views are included in the next content } \\
\text { resides teaching }\end{array}$ \\
\hline
\end{tabular}

\section{Traditional Assessment Assessments of 21st Century contemporary}

In traditional evaluation is often provided in writing with alternative response assessment means open to evaluation forms Timing of assessment Assessments is continuous throughout the entire school year

The grade depends only on the basis of a knowledge controlling rating depends on many things

Rating marked with grade rating is oriented progress

Assessment instruments are subject to change norms for assessment instruments subject to different criteria

The evaluation process is separate from the teaching evaluation process related to the learning process

Success depends on the memorization of information presented in the certain moments of success is determined through cooperation and negotiation over a longer period 
Understanding measured by linguistic ability (language) and logical / mathematical understanding is measured in the choice of real-life problems

The correct answer is testimony to the efforts and learning of students' views of students used to understand their perception and that those views are included in the next content resides teaching

\section{Characteristics of a successful modern teaching as perceived by pupils and teachers}

According to students, characteristics of a successful teaching are: gravity at work, clarity in teaching, assessment right, to use different methods during the explanation, object recognition, sense of humor, love of students, recognition of students' psychological side, counseling etc. Students teacher describes how effective teachers who have professional preparation, communication skills, creativity, is utilizing the new teaching techniques, originators, modest, and teacher who uses a sense of humor. During the discussion it became clear that one of the main characteristics of a successful teacher was established good relationship with students. According to the students, a teacher is good, when there is good ability to communicate with students, when students understand the situation when advising, respects, is close to them and good behavior.

\begin{tabular}{|l|l|}
\hline Teacher's responses & Students responses \\
\hline Seriousness in the work & Professional Preparation \\
\hline Knowing the psychological side of expressive & Student's ability \\
\hline To have a sense of humor & To retrieve different teaching strategies \\
\hline Be a hard worker & Correctness, Attitude \\
\hline Keeping different activities & Use of new teaching techniques \\
\hline
\end{tabular}

Characteristics which were praised by students and teachers for a successful were professional ways of teaching. Cognitive characteristics discussed the most were: professional preparation, variety of teaching methods, the use of attractive, clarity in teaching, expressive skills, knowledge of the case, implementation of the educational program, the fair valuation. An effective teachers, according to them, is a teacher who appreciates straight and equips students more opportunities to demonstrate their learning. According to contemporary teaching successful students are those who explain the clarity of explaining the main features of the unit development, etc. also teaching successful contemporary or evaluate those teachers who use modern teaching techniques. Some of the features of a modern teaching as perceived by teachers and learning are:

\section{Responses students' responses teacher}

Seriousness in the work Professional Preparation

Knowing the psychological side of expressive ability students

To have a sense of humor To retrieve different teaching strategies

Be worker correctness, attitude

Keeping different activities use of new teaching techniques

The role of the teacher is to analyze, plan and implement the learning process through teacher lead at all stages of the theoretical and practical. The role of students is learning to acquire knowledge, develop cognitive skills, to form habits, skills and attitudes. 


\section{Teaching and learning}

Teaching and learning are fundamental concepts and actions in achieving educational goals and objectives, and education, in terms and conditions of the institutional organization of the event composite and individual and social value. Teaching and learning the historical development have undergone many changes, which are reflected both in the overall organizational structure, and in particular its structures, which are reflected in the constituent elements of teaching articulation of the various stages of the process of teaching work in whole. Today when we talk about contemporary learning, we can say that this activity has reached the highest level of development in terms of the process of recognition and learning, both in terms of shapes and didactic strategies for organizing actions and functional development of forms and other actions of the teaching work. Learning and teaching process are a didactic communications activities planned and organized, with implementing the objectives and tasks of learning, this activity that takes place under the leadership of teaching and full interactive engagement of students. Learning as pedagogical activity takes place on the organizational structure of external and of internal organization, which expressed stages of working-educational progress and reports to interactive character interactions promote participation in training. As organized process, teaching is an activity which achieved the realization of a certain goal and tasks set. We mainly didactic literature teaching is two models:

1. Direct teaching, with the objective of focusing on rapid achievement of mastery of facts, rules and the formation of habits for them, and content of the course is divided into small steps that easily absorbed; the learning process is supervised by teachers.

2. The teaching of indirect central objective of student involvement in the review and investigation, which helps in the formation and development of concepts in the form of models. Teaching through questions that directs students leads them to discover and generalize, by evaluating their responses. Teaching as interpersonal activities, is the act of teaching directed by the teacher, who plans and organizes the development of the teaching process and learning, to develop processes with students and other collaborators in learning, which has purpose to analyze and evaluation of teaching work to develop. Teaching as a rational process of organizing ergo-didactic activity takes place on the requirements for the transmission and acquisition of human experience, summarized and collated the contents of the plan and the curriculum, the development of vocational skills and positive attitudes of students.

\section{Techniques that NIAC Methods- Student in the Center}

Given that recent developments in the field of education are making new strides in improving the quality of teaching have also changed the method of teaching or words departure from traditional teaching methods to modern teaching method focusing in Ores learning to discussion and debate thus presenting the arguments for a matter of two opposing groups to the listeners, following a standard performance. An important factor which helps a modern teaching are the conditions in which the teaching, learning tools play an important role in the progress of learning such as radio, television, illustration through pictures etc. For now developed a modern teaching methods and student-centered techniques in the teaching process used an entirely techniques and methods. In modern school, apply not one, but a range of teaching methodologies, common of which is the placement of students in the center. By such methodology would mention: Teaching and students through projects, teaching and programmed lessons, learning and discovering, teaching and learning by solving problems and active learning etc. Methods and learning techniques are standard procedures that use teachers in collaboration with students for presenting and developing materials teaching activities to achieve goals and learning objectives. In the literature related to learning methods, in our country and beyond, there is a tendency to give priority to those methods indication that put into action the student, is the interaction between the parties participating in the lesson. Today in the process of contemporary teaching there are a range of techniques that NIAC aim to improve teaching, number of techniques is great but we will only focus to some techniques that are more in use, but will look at research analysis paper how NIAC knowledge and working teachers with modern teaching techniques. Today in use are a range of modern techniques in teaching starting from Brainstorming techniques, Wien diagram, five range, cluster, concepts table, Insert technique, technique save last word for me, learning techniques etc. 


\section{Analysis, interpretation of data}

According to data obtained from the field and discussions we have had with the teacher have these results that will be presented graphically illustrated.

A) In the first question you have showed teachers if you know modern techniques of teaching have these results: $92 \%$ of them declared for Yes to NIAC knowledge of contemporary techniques of student-centered teaching and $8 \%$ of them declared that not. It is obvious that the majority of teaching NIAC knowledge of modern techniques of teaching the student center.

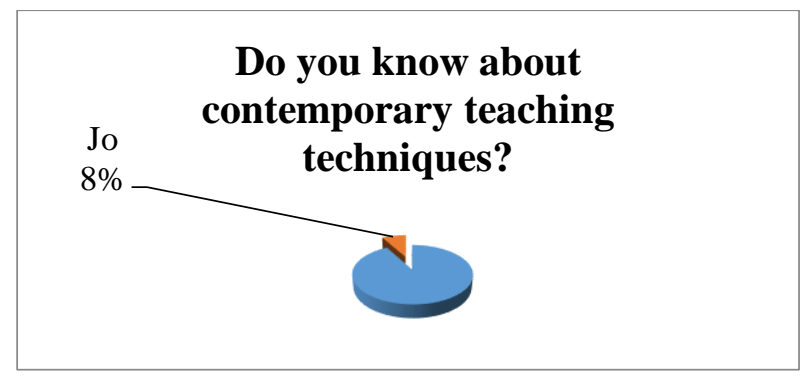

B) The second question turns out you get this knowledge on modern techniques of teaching $65 \%$ of teaching declared by teaching while $35 \%$ declared by the master in teaching postgraduate studies. Teachers are trained through various programs, the majority part of them are part of the training received by new acquaintances on improving teaching techniques, and the development of modern teaching.

\section{Where did you get this information about contemporary teaching techniques?}

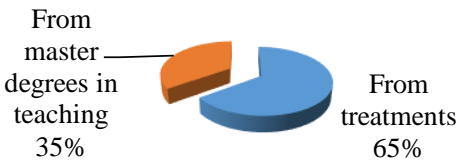

C) When asked how you set the students in the class considering lowering the student forms have the following results: In the group are reduced $69 \%$ of the students, the couple is seated $30 \%$ and $1 \%$ are sitting on. The majority of students are clearly sitting in groups then $30 \%$ are sitting couple but mostly are sitting male female and $1 \%$ are those children who wish to be alone and have no desire to join their friends in class mainly consist of Roma and Egyptian community. 


\section{How did you place students in the} classropom??

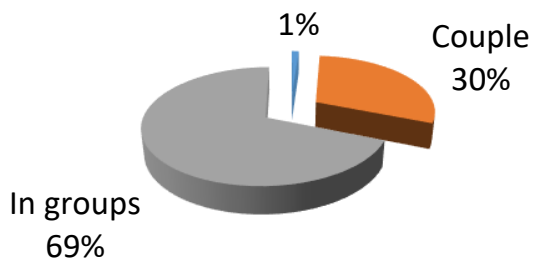

D) The question in cases in which the retrieve mostly retrieve contemporary teaching techniques have the following results: $52 \%$ declared that the techniques used in the case of the Albanian language, $20 \%$ of them stated that they use in letting Nature and Society, $16 \%$ of teachers stated that they use in the teaching of English language and $12 \%$ in mathematics. From the results obtained shows that the use of techniques learner-centered teaching mostly realized in the case of the Albanian language.

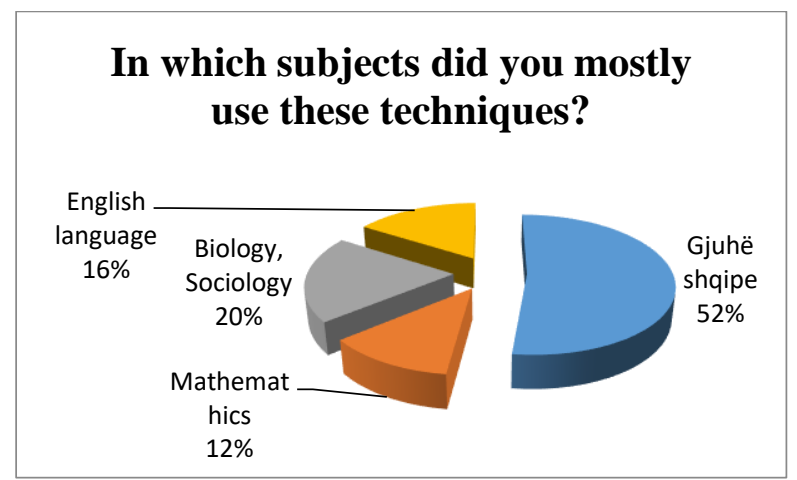

E) In the question which techniques usually start the class $70 \%$ of the teachers stated that the use Techniques Brainstorm. While $30 \%$ of them declared that the use Techniques cluster seen that the majority of teachers use in the early part ores in Introductory or stated differently in advocacy techniques Brainstorming.

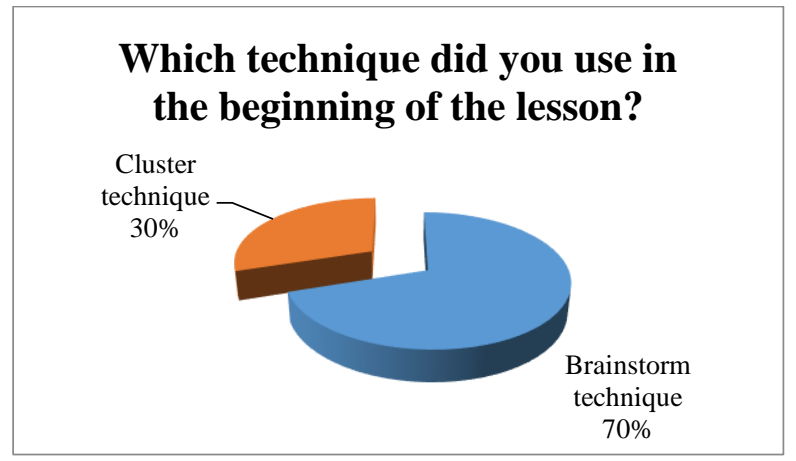

F) The question of which techniques they mostly use a lecturer in the central part and the final part or the end of the class have these data: $50 \%$ declared to five range, 18\% for Table Concepts, $16 \%$ for Insert technique and also $16 \%$ Techniques Table $\mathrm{T}$, shows that there is greater use five range techniques. 


\section{Which technique did you mostly use?}

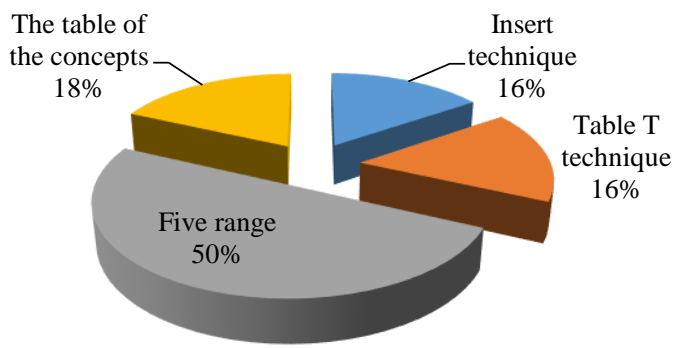

\section{Conclusions and Recommendations}

Teaching and learning are two basic processes underlying together. The two together are important processes and difficult. Modern Teaching is a complex relationship between students and Teachers. For years has dominated the traditional teaching with the teacher teaching center, and now the roles have changed today in the modern teaching is student centered learning, necessity has led to changing needs and improve teaching. Using modern teaching techniques in modern teaching contributes to an efficient and successful teaching. The usage of teaching techniques enables students to develop critical thinking, as modern teaching learning develops through demonstration etc. Gradually the teacher's role has changed from an authoritarian personality in a cooperative personality, etc. helpful advisory.

- The Ministry of Education should improve environmental conditions for learning.

- To access training for all teachers who are in working process.

- School leaders should involve teachers in training.

- Train teachers to share experiences with their students.

\section{Bibliography}

[1] Ismaili, Dr. Khadija, Teaching Tools and Critical Thinking, Pristina, 2013.

[2] Moses, Dr. Bardhyl, Teaching Methodology, Pegi, 2003.

[3] Manual, Planning and Evaluation of Education, KEC, Prishtina, 2001.

[4] Nuredini, Dr. Vaxhid, Theory of Learning, learner-centered, Pristina, 2012.

[5] Authors group, Teacher and Teaching, Vllamasi, Tirana, 2013.

[6] Fullan, Michael, The New Meaning of Educational Change, CDE, Tirana, 2010.

[7] Pupovci Tour, Child Rights and Ethics of Teaching, KEC

[8] Xhejlane Ali, How to be a Successful Teacher, spark, Pristina, 2012.

[9] Zylfiu, Dr. Niyazi, Learning Theory and Didactic Processes, Pristina, 2011

[10] Zhitija. Mr. Majlinda, Role of Teachers in Classrooms Learner CENTER 